\title{
Модель формування кінезіологічної компетентності майбутніх фахівців 3 фрізичної культури і спорту у процесі їх професійної підготовки
}

\author{
${ }^{1}$ Юлія Петренко \\ ${ }^{1}$ Володимир Ашанін \\ ${ }^{2}$ Юрій Петренко
}

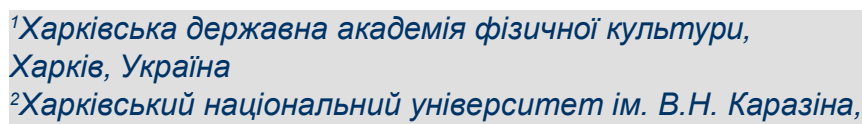

Харків, Україна

\begin{abstract}
Мета: обгрунтувати модель фрормування кінезіологічної компетентності майбутніх фрахівців з фрізичної культури і спорmy.

Матеріал і методи: аналіз і узагальнення фрілософсько-методологічної, психолого-педагогічної та навчальнометодичної літератури, методи моделювання та структурно-системного аналізу дали можливість з'ясувати сучасний стантеоріїтапрактикипідвищенняякостіпедагогічногопроцесу, систематизуватитаузагальнитиінформаціюпродосліджуваний об'єкт фоормування кінезіологічної компетентності майбутніх фрахівців з фрізичної культури і спорту у процесі їх профресійної підготовки.

Результати: розглянуто сутність моделі фрормування кінезіологічної компетентності майбутніх фрахівців з фрізичної культури іспорту, яка базується на системномуаналізі підходів щодо підготовки фрахівців у сфрері фрізичної культури і спорту. Зазначено передумови фрормування кінезіологічної компетентності майбутніх фрахівців з фрізичної культури $i$ спорту у процесі їх професійної підготовки.

Висновки: в результаті дослідження обгрунтовано структуру моделі формування кінезіологічної компетентності майбутніх фрахівців з фрізичної культури і спорту у процесі їх профресійної підготовки.
\end{abstract}

Ключові слова: фрахівці, фрізична культура і спорт, профресійна підготовка, модель, кінезіологічна компетентність.

\section{Вступ}

Сучасна професійна освіта передбачає реформування та удосконалення системи фахової підготовки майбутніх фрахівців з фізичної культури та спорту. Якісна підготовка таких фахівців на всіх рівнях вищої педагогічної освіти повинна бути зосереджена на формуванні відповідних професійних компетентностей, які обумовлені певними суперечностями в сучасному суспільстві $[1,10,11]$.

Вимоги до профресіоналізму сучасних фрахівців з фрізичної культури і спорту виявляються в об'єктивних характеристиках та вимогах до професійної діяльності фахівця певного кваліфрікаційного рівня, нормах і вимогах до якостей особистості фахівця. Ці вимоги впливають на визначення структури і змісту професійної компетентності майбутніх фахівців з фрізичної культури і спорту, яка $є$ метою профресійної підготовки.

Однією з проблем вбачається забезпечення раціонального використання людиною рухових можливостей, що у контексті професійної підготовки фрахівців з фрізичної культури і спорту інтегрується у кінезіологічну компетентність $[2,3,5]$.

Зв'язок дослідження 3 науковими програмами, планами, темами. Проведене дослідження виконано в межах фундаментальної теми наукової-дослідної роботи у сфрері фрізичної культури і спорту кафедри інформатики та біомеханіки Харківської державної академії фрізичної культури на 2019-2024 рр. «Науково-методичні основи використання інформаційних технологій приформуванні професійної компетентності фрахівців фізичної культури і спорту» (№0119U103207).

Мета дослідження - обґрунтувати модель формування кінезіологічної компетентності майбутніх фрахів фрізичної культури і спорту.

Завдання дослідження.

1. Провести аналіз проблеми формування кінезіологічної компетентності майбутніх фрахівців з фізичної культури і спорту у процесі їх профресійної підготовки.

2. Теоретично обґрунтувати модель формування кінезіологічної компетентності майбутніх фрахівців з фізичної культури і спорту у процесі їх професійної підготовки.

\section{Матеріал і методидослідження}

Аналіз і узагальнення фрілософсько-методологічної, психолого-педагогічної та навчально-методичної літератури, методи моделювання та структурно-системного аналізу, дали можливість з'ясувати сучасний стан теорії та практики підвищення якості педагогічного процесу, систематизувати та узагальнити інформацію про досліджуваний об'єкт та обґрунтувати модель фрормування кінезіологічної компетентності майбутніх фрахівців з фізичної культури і спорту у процесі їх професійної підготовки.

\section{Результати дослідження}

Системна методологія у наукових дослідженнях призвела до поняття того, що не можна ототожнювати систему та об'єкт. Система служить в основному теоретичним засобом представлення сутності об'єкта. Для виділення системи із середовища, необхідно виходити із уявлень про функції, загальну мету, компоненти та ресурси, а також механізми управління системою [4].

Поняття «модель» та «педагогічне моделювання» в даний час широко застосовуються у професійній підготовці фахівців різних галузей. Так, «модель» - це образ (уявний 


\section{СЛОБОЖАНСЬКИЙ НАУКОВО-СПОРТИВНИЙ ВІСНИК:}

\section{Матеріали XIX Міжнародної науково-практичної конференції «Фізична культура, спорт і здоров'я: стан, проблеми та перспективи»}

або умовний: зображення, опис, схема, креслення, графрік або план, карта та ін.) будь-якого об'єкту, процесу або явища (оригіналу даної моделі).

Модель виконує чіткі фуннції:

1. Визначає компоненти, які становлять систему.

2. Схематично та реально відображає зв'язки між компонентами, до того ж зв'язки всередині модельованого об'єкта можна порівняти зі зв'язками всередині моделі.

3. $€$ інструментом для порівняльного вивчення різних ознак явища, процесу.

«Педагогічне моделювання» $є$ процесом конструювання моделі педагогічної системи і постановки експериментів на цій моделі з метою або зрозуміти поведінку системи, або оцінити функціонування цієї системи.

В межах проведеного нами дослідження педагогіч не моделювання в закладах вищої освіти галузі фрізичної культури та спорту можна розділити на п'ять етапів:

1. Постановкаціліпедагогічногомоделюваннящодо підвищення рівня сорормованості професійної компетентності фахівців з фрізичної культури і спорту.

2. Встановлення особливостей та визначення функцій педагогічного моделювання під час формування профресійної компетентності фрахівців з фрізичної культури спорту.

3. Розробка графічної моделі формування професійної компетентності фрахівців з фрізичної культури і спорту.

4. Практичне впровадження моделі формування профресійної компетентності фрахівців з фрізичної культури і спорту.

5. Аналіз та обробка результатів впровадження педагогічного моделювання у навчально-виховний процес ЗВО та внесення певних коректив.

Структура моделі педагогічної системи включає: мету, заради якої вона створюється та функціонує, народжуючи педагогічний результат, зміст навчання, засоби навчання, форми та методи навчання, навчальну діяльність студента, навчальнутанауковудіяльністьвикладача тарезультат фонкціонування педагогічної системи, її «продукт».

Ґрунтовний аналіз наукових джерел засвідчив, щоза останнє десятиліття були проведені дослідження щодо концептуальних основ професійної підготовки фахівців у галузі фрізичної культури і спорту (В.С. Ашанін, В.В. Приходько, О.А. Томенко та ін.); теоретичних й методичних засад професійної підготовки майбутніх учителів фрізичної культури (О.Ю. Ажиппо, П.Б. Джуринський, О.М. Печко та ін.); майбутніхтренерів-викладачів (Є.О.Павлюк, А.В. Сватьєв та ін.), майбутніх фахівців з фізичної реабілітації та фахівців зі здоров'я людини (Н.О. Бєлікова, Ю.О. Лянной та ін.) [8].

Однак, виявлено, що проблема побудови моделі фрормуваннякінезіологічноїкомпетентностімайбутніх фахівців з фрізичної культури і спорту у процесі їх професійної підготовки у закладах вищої освіти не була предметом широкого кола досліджень вітчизняних та зарубіжних науковців, тому актуальність означеної проблеми обумовлена, поперше, зростаючим попитом українського суспільствана інноваційні різновиди рухової активності, по-друге, недостатньою зорієнтованістю професійної підготовки фрахівців з фізичної культури і спорту на кінезіологічні знання уміння, відсутністю ефективних моделей фрормування у них кінезіологічної компетентності, по-третє, відсутністю відповідного навчально-методичного забезпечення з ви- користанням інформаційно-комунікаційних технологій $[7$, $9,12]$.

3 метою фрормування у майбутніх фрахівців з фрізичної культури і спорту кінезіологічної компетентності розглянемо розроблену авторську модель (рис. 1), яка складається з чотирьох блоків: цільового, теоретико-методологічного, змістово-процесуального, оцінно-результативного [6, 8].

Цільовий блок складається з мети та завдань.

Теоретико-методологічний блок об'єднує методологічні підходи та принципи. Змістово-операційний блок визначається навчальним планом, навчальними програмами 3 дисциплін, містить форми, методи і засоби навчання, орієнтовані на формування кінезіологічної компетентності майбутніх фрахівців з фрізичного виховання та спорту у процесі професійної підготовки. Оцінно-результативний блок передбачає виокремлення структури кінезіологічної компетентності майбутніх фрахівців з фізичного виховання та спорту, моніторинг рівнів сорормованості кінезіологічної компетентності майбутніх фрахівців фізичного виховання та спорту через систему відповідних критеріїв та показників на результат.

Одним із показників високого статусу держави є соціальна потреба у професійно підготовлених фахівцях 3 фрізичної культури і спорту з професійними компетентностями, зокрема, кінезіологічною. Тому, у цільовому блоці моделі визначено мету - формування компонентів кінезіологічної компетентності майбутніх фрахівців з фрізичної культури і спорту у процесі професійної підготовки.

Теоретико-методологічний блок моделі розглядається з позиції професіографічного, аксіологічного, системного, праксеологічного, особистісно-діяльнісного, інтегративного та компетентнісного підходів до формування кінезіологічної компетентності майбутніх фахівців з фізичної культури і спорту у процесі професійної підготовкияк сукупності закономірних, функціонально пов'язаних компонентів, щоутворюютьпевну ціліснупедагогічнусистему; загальнодидактичнихпринципів: індивідуалізації, міцності знань, умінь і навичок, доступності, свідомості, активності і самостійності, систематичності і послідовності, науковості, наочності, інтеграції; принципів кінезіології: фуннкціонального аналізу рухових дій; структурності побудови системи рухів; цілісності дії; свідомої цілеспрямованості системи рухів; принципів врахування основ кінезіології у процесі профресійної діяльності фрахівців з фрізичної культури і спорту: кінезіологічної спрямованості; циклічності та безперервності; ефективності спортивної техніки та педагогічної майстерності; соціокультурної спрямованості; педагогічної доцільності застосування IT.

Для ефективного фрормування кінезіологічної компетентності майбутніх фрахівців з фрізичної культури і спорту у змістово-процесуальному блоці вдосконалено зміст навчально-методичного забезпечення, методи і засоби навчання та форми організації навчальної діяльності студентів.

Оцінно-результативний блок описує компоненти: гносеологічний, праксеологічний, поведінковий; критерії та показники: предметно-знаннєвий критерій - показник: обсяг кінезіологічних знань, техніко-операційний критерій - показники: обсяг кінезіологічних умінь; володіння методикою навчання руховим діям; особистісний критерій - показники: мотивація до рухових видів діяльності, потреба у досягненнях, вольова регуляція; рівні сформованості кінезіологічної компетентності майбутніх фахівців з фізичної культури і спорту: реконструктивний, базовий, 
СЛОБОЖАНСЬКИЙ НАУКОВО-СПОРТИВНИЙ ВІСНИК:

Матеріали XIX Міжнародної науково-практичної конференції «Фізична культура, спорт і здоров'я: стан, проблеми та перспективи»

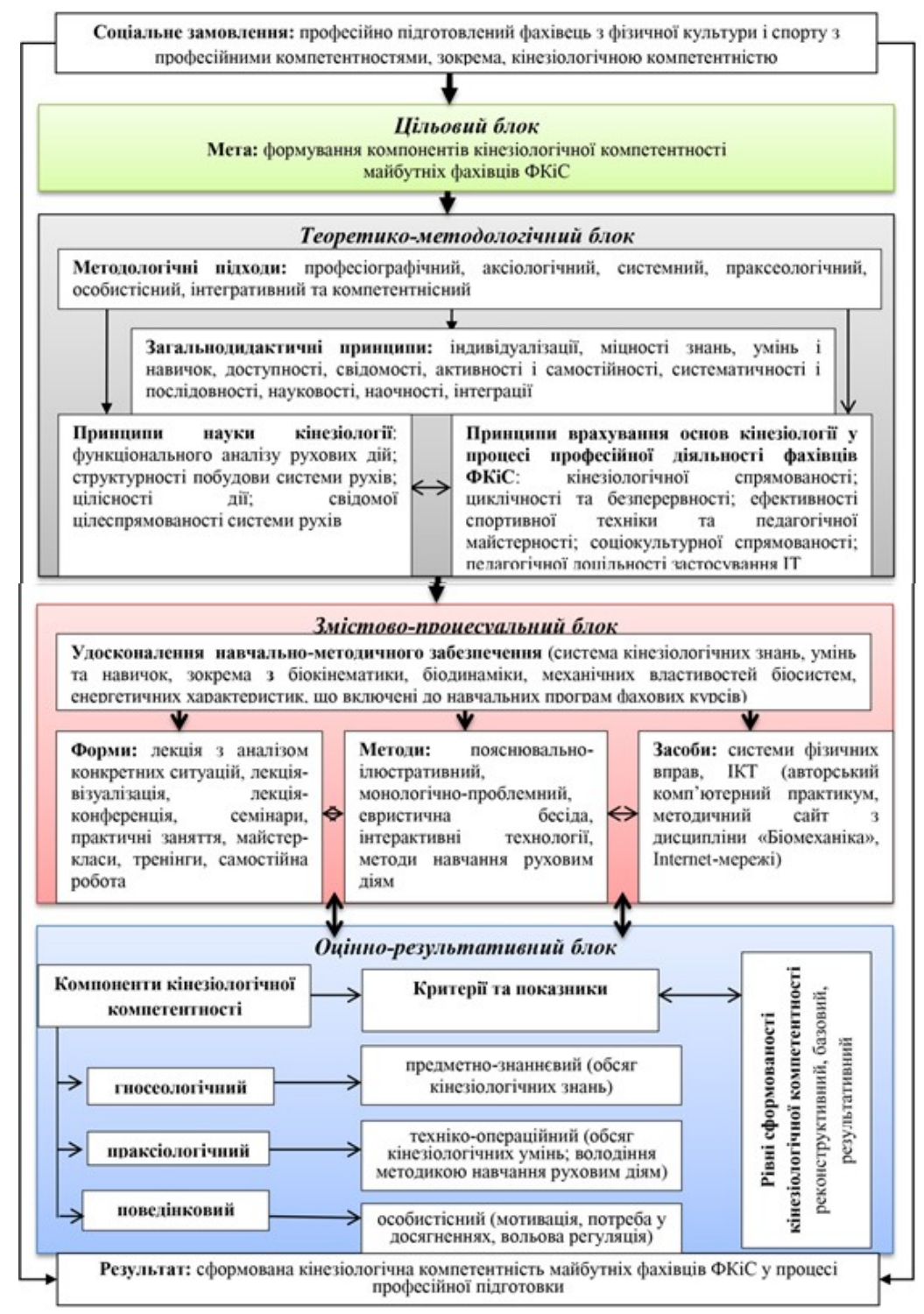

Рис. 1. Модель формування кінезіологічної компетентності майбутніх фахівців з фізичної культури і спорту у процесі професійної підготовки

результативний.

\section{Висновки /Дискусія}

В результаті дослідження встановлено та обґрунтовано методологічну та функціональну структуру моделі формування кінезіологічної компетентності. Представлена модель дасть змогу провести усвідомлений пошук оптимальних шляхів формування кінезіологічної компетентності майбутніх фахівців з фрізичної культури і спорту у процесі їх професійної підготовки. У цілому вважаємо, що реалізація моделі передбачає активізацію процесу навчання через оптимізацію структури та змісту навчання через вплив виокремлених організаційно-педагогічних умов, які представлені у теоретико-методологічному та змістово-процесуальному блоках.

Перспективи подальших досліджень полягають у вивченні проблеми формування кінезіологічної компетентності майбутніх фрахівців з фрізичної культури і спорту у процесі проходження педагогічноїпрактики.

Конфлікт інтересів. Автор заявляє, що немає конфлікту інтересів, який може сприйматись таким, що може завдати шкоди неупередженості статті.

Джерела фінансування. Ця стаття не отримала фінансової підтримки від державної, громадської або комерційної організації.

\section{Список посилань}

1. Ашанін В.С., Мудрик В.І., Андрєєв М.В. (2019), Проблеми формування професійної компетентності майбутніх фрахівців фізичної культури і спорту, Харків.

2. Голомазов С.В. (2003), Кинезиология точностных действий человека, М.:СпортАкадемПрес.

3. Дмитриев С.В. (2003), Учитесь читать движение, чтобы строить действие, Н.Новгород: Изд-во НГПУ. 


\section{СЛОБОЖАНСЬКИЙ НАУКОВО-СПОРТИВНИЙ ВІСНИК:}

\section{Матеріали XIX Міжнародної науково-практичної конференції «Фізична культура, спорт і здоров'я: стан, проблеми та перспективи»}

4. Жилин Д.М. (2003), Теория систем, М. : Едиториал. УРСС

5. Курысь В.Н. (2013), Биомеханика. Познание телесно-двигательного упражнения: учебное пособие, М. : Советский спорт 6. Петренко Ю. І. (2018), Основні структурні компоненти кінезіологічної компетентності майбутніх фрахівців фрізичної культури і спорту, Педагогічні науки: теорія, історія, інноваційні технології, №5 (79), С. 184-199.

7. Петренко Ю. І. (2018), Теоретичні основи формування кінезіологічної компетентності майбутніх фрахівців фрізичної культури і спорту засобами інформаційних технологій, Фізико-математична освіта, № 1 (2), С. $22-25$

8. Петренко Ю.І. (2019), Формування кінезіологічної компетентності майбутніх фрахівців з фрізичної культури і спорту у процесі їх профресійної підготовки : дис. канд. пед. наук : 13.00 .04 , Суми, 306 с.

9. Приходько В.В., Дзюбенко М.І. (2018), Місце кінезіологічної компетентності при вивченні природничо-наукових дисциплін у процесі професійної підготовки фрахівців фізичної культури і спорту, Гуманізація навчально-виховного процесу, № 3(89), C. $116-126$

10. Тимошенко О. В. (2009), Теоретико-методичні засади оптимізації професійної підготовки вчителів фрізичної культури у вищих навчальних закладах : дис. докт. пед. наук : 13.00.04, Київ, 587 с.

11. Filenko, L., Ashanin, V., Basenko, O., Petrenko, Y., Poltoratska, G., Tserkovna, O., Kalmykova, Y., Kalmykov, S., Petrenko, Y. (2017), Teaching and learning informatization at the universities of physical culture, Journal of Physical Education and Sport, 17(4), 2454-2461.

12. Petrenko Yu.I., Zigunov V.M., Balashov D.I., Bermudes D.V. and Shyshenko I.V. (2019), Use of the Software Biomechanics in Physical Culture and Sports Specialists' Preparation, 42 international convention on information and communication technology, electronics and microelectronics (20-24.05.2019, Opatija, Croatia)), 915-919.

Стаття надійшла до редакції: 11.11 .2019 р.

Опубліковано: 30.12.2019 р.

Аннотация. Юлия Петренко, Владимир Ашанин, Юрий Петренко. Модель формирования кинезиологической компетентности будущих специалистов физической культуры и спорта в процессе их профессиональной подготовки. Цель: обосновать модель формирования кинезиологической компетентности будущих специалистов по физической культуре и спорту. Материал и методы: анализ и обобщение философско-методологической, психолого-педагогической и учебнометодической литературы, методы моделирования и структурно-системного анализа позволили выяснить современное состояние теории и практики повышения качества педагогического процесса, систематизировать и обобщить информацию об исследуемом объекте формирования кинезиологической компетентности будущих специалистов по ффизической культуре и спорту в прочессе их профессси- ональной подготовки. Результаты: рассмотрено сущность модели формирования кинезиологической компетентности будущих специалистов по физической культуре и спорту, которая базируется на системном анализе подходов по подготовке специалистов в сфрере фризической культуры и спорта. Указано предпосылки формирования кинезиологической компетентности будущих специа- пистов по физической культуре и спорту в процессе их профессиональной подготовки. Выводы: в результате исследования обосно- вано структуру модели формирования кинезиологической компетентности будущих специалистов по физической культуре и спорту в процессе их профессиональной подготовки.

Ключевые слова: специалисты, ффизическая культура и спорт, профрессиональная подготовка, модель, кинезиологическая компетентность.

Abstract. Yuliia Petrenko, Volodymyr Ashanin, Yuriy Petrenko. A model for the formation of kinesiological competence of future specialists in physical education and sports in the process of their professional training. Purpose: to substantiate a model for the formation of kinesiological competence of future specialists in physical education and sports. Material and methods: analysis and generalization of philosophical-methodological, psychological, pedagogical and educational-methodical literature, modeling and structural-system analysis methods made it possible to find out the current state of theory and practice of improving the quality of the pedagogical process, to systematize and generalize information about the object under study for the formation of kinesiological competence of the future physical education and sports specialists in the process of their professional training. Results: the essence of the model for the formation of kinesiological competence of future specialists in physical education and sports is considered, which is based on a systematic analysis of approaches to training specialists in the field of physical education and sports. The prerequisites for the formation of kinesiological competence of future specialists in physical education and sports in the process of their professional training are indicated. Conclusions: as a result of the study, the structure of the model for the formation of kinesiological competence of future specialists in physical education and sports in the process of their professional training is substantiated.

Keywords: specialists, physical education and sport, professional training, model, kinesiology competence.

\section{References}

1. Ashanin V.S., Mudrik V.I., Andryeyev M.V. (2019), Problemi formuvannya profesijnoyi kompetentnosti majbutnih fahivciv fizichnoyi kulturi i sportu, Harkiv. 169 p. (in Ukr.).

2. Golomazov S.V. (2003), Kineziologiya tochnostnyh dejstvij cheloveka, M.:SportAkademPres. 228 p. (in Russ.).

3. Dmitriev S.V. (2003), Uchites chitat dvizhenie, chtoby stroit dejstvie, N. Novgorod: Izd-vo NGPU. 178 p. (in Russ.).

4. Zhilin D.M. (2003), Teoriya sistem, M. : Editorial. URSS. 184 p. (in Russ.).

5. Kurys V.N. (2013), Biomehanika. Poznanie telesno-dvigatelnogo uprazhneniya: uchebnoe posobie, M. : Sovetskij sport. 368 p.(in Russ.).

6. PetrenkoYu. I. (2018), Osnovni strukturni komponenti kineziologichnoyi kompetentnosti majbutnih fahivciv fizichnoyi kulturi i sportu, Pedagogichni nauki: teoriya, istoriya, innovacijni tehnologiyi, №5 (79), pp. 184-199.(in Ukr.).

7. PetrenkoYu. I. (2018), Teoretichni osnovi formuvannya kineziologichnoyi kompetentnosti majbutnih fahivciv fizichnoyi kulturi i sportu zasobami informacijnih tehnologij, Fiziko-matematichna osvita, № 1 (2), pp. 22-25.(in Ukr.).

8. PetrenkoYu.I. (2019), Formuvannya kineziologichnoyi kompetentnosti majbutnih fahivciv z fizichnoyi kulturi i sportu u procesi yih profesijnoyi pidgotovki : dis. kand. ped. nauk: 13.00.04, Sumi, 306 p.(in Ukr.)

9. Prihodko V.V., Dzyubenko M.I. (2018), Misce kineziologichnoyi kompetentnosti pri vivchenni prirodnicho-naukovih disciplin u procesi profesijnoyi pidgotovki fahivciv fizichnoyi kulturi i sportu, Gumanizaciya navchalno-vihovnogo procesu, № 3(89), pp.116126.(in Ukr.).

10. Timoshenko O. V. (2009), Teoretiko-metodichni zasadi optimizaciyi profesijnoyi pidgotovki vchiteliv fizichnoyi kulturi u vishih navchalnih zakladah : dis. ... dokt. ped. nauk : 13.00.04, Kiyiv, 587 p.(in Ukr.).

11. Filenko, L., Ashanin, V., Basenko, O., Petrenko, Y.,Poltoratska, G., Tserkovna, O., Kalmykova, Y., Kalmykov, S., Petrenko, Y. (2017), Teaching and learning informatization at the universities of physical culture, Journal of Physical Education and Sport, 17(4), pp. 2454-2461. (in Eng.).

12. PetrenkoYu.I., Zigunov V.M., Balashov D.I., Bermudes D.V. and Shyshenko I.V. (2019), Use of the Software Biomechanics in Physical Culture and Sports Specialists' Preparation, 42 international convention on information and communication technology, electronics and microelectronics (20-24.05.2019, Opatija, Croatia)), pp. 915-919. (in Eng.). 
СЛОБОЖАНСЬКИЙ НАУКОВО-СПОРТИВНИЙ ВІСНИК:

Матеріали XIX Міжнародної науково-практичної конференції «Фізична культура, спорт і здоров'я: стан, проблеми та перспективи»

\section{Відомості про авторів / Information about the Authors}

Петренко Юлія Іванівна: кандидат педагогічних наук, Харківська державна академія фрізичної культури: вул. Клочківська 99, Харків, 61058, Україна.

Петренко Юлия Ивановна: кандидат педагогических наук, Харьковская государственная академия фризической культуры: ул. Клочковская 99, г. Харьков, 61058, Украина.

Yulia Petrenko: PhD (Pedagogical Science), Kharkiv State Academy of Physical Culture: Klochkovskaya str. 99, Kharkiv, 61058, Ukraine.

orcid .org /0000-0002-6549-3729 E- E E -mail: horbatenko1604@gmail.ru

Ашанін Володимир Семенович: кандидат фізико-математичних наук, професор, Харківська державна академія фізичної культури: вул. Клочківська 99, Харків, 61058, Україна.

Ашанин Владимир Семёнович: кандидат физико-математических наук,, профессор, Харьковская государственная академия фиизической культуры: ул. Клочковская 99, г. Харьков, 61058, Украина.

Volodymyr Ashanin: PhD (Physics-Mathematics), Professor, Kharkiv State Academy of Physic al Culture: Klochkivska str. 99, Kharkiv, 61058, Ukraine.

ORCID.ORG /0000-0002-4705-9339

E -mail: ashaninvladimir47@gmail.com

Петренко Юрій Михайлович: Харківський національний університет ім. В. Н. Каразіна: пл. Свободи 2, м. Харків, 61022,Україна.

Петренко Юрий Михайлович: Харьковский национальный университет им. В. Н. Каразина: пл. Свободы 2, г. Харьков, 61022, Украина.

Yuriy Petrenko: Karazin Kharkov National University: Svobody Sq. 2, 61022, Kharkiv, Ukraine.

orcid .org 10000-0001-8169-88-07 E- e- E -mail: petrenkofytbol@gmail.com 